\title{
Grand Challenges in Transportation and Transit Systems
}

\author{
Sakdirat Kaewunruen ${ }^{1 *}$, Joseph M. Sussman ${ }^{2}$ and Akira Matsumoto ${ }^{3}$ \\ ${ }^{1}$ Birmingham Centre for Railway Research and Education, School of Engineering, The University of Birmingham, \\ Birmingham, UK, ${ }^{2}$ Department of Civil and Environmental Engineering and Engineering Systems, Massachusetts Institute of \\ Technology, Cambridge, MA, USA, ${ }^{3}$ Japan Transport Safety Board, Tokyo, Japan
}

Transportation and transit systems draw upon broad spectra of research fields due to the diversity and interconnectivity of transport modes, including road, rail, aviation, pipeline, maritime, or even aerospace. These systems have evolved over centuries to be considerably more efficient and environment-friendly for a wide range of customers. The fundamental principle "safety first" is still the key priority in most research today. However, thanks to extensive interface with various customers; research and innovation in practices have shifted from optimizing functional purposes and targets through each stage of life cycle toward modernization, reliability, resilience, and better quality of life. These initiatives additionally coincide with the grand challenges for engineering proposed by the National Academy of Engineering and the United Nations' Millennium Development Goals (National Academy of Engineering, 2015).

OPEN ACCESS

Edited by:

Cholachat Rujikiatkamjorn, University of Wollongong, Australia

Reviewed by:

Sanjay Shrawan Nimbalkar, University of Wollongong, Australia

*Correspondence:

Sakdirat Kaewunruen sakdirat@hotmail.com,

s.kaewunruen@bham.ac.uk

Specialty section:

This article was submitted to

Transportation and Transit Systems,

a section of the journal

Frontiers in Built Environment

Received: 26 January 2016

Accepted: 17 February 2016

Published: 24 February 2016

Citation:

Kaewunruen S, Sussman JM and Matsumoto A (2016) Grand Challenges in Transportation and Transit Systems.

Front. Built Environ. 2:4. doi: 10.3389/fbuil.2016.00004
Keywords: grand challenges, transportation, transit systems, infrastructure, economic and social impacts, sociotechnical system

\section{INTRODUCTION}

Transportation and transit systems play a critical role in urban development, mobility, and economic growth of societies, regions, nations, and even continents. There are a variety of transportation and transit systems, including land transportation (road, rail, and maglev), aviation (airplanes, rockets), maritime (ferries, ships, ports), and pipeline (tunneling, risers, hyperloop). These complex sociotechnical systems are interconnected, and undoubtedly, the behind-the-scene catalyst is essential for building new capabilities and innovation as well as improving efficacy and effectiveness of other businesses and industry sectors, such as resources logistics, agriculture, real estate, manufacturing, and tourism. However, it is unfortunate that not all original and novel transportation discoveries, strategies, and policies are automatically adopted into industry standards, real-world practices, or frontline products. The pathway to successful adoption and translation of research and innovation depends largely on long track records of experiments, failures, trials and errors, redesigns, optimizations, verifications, and technological practicality.

Transportation and transit systems face significant challenges at the intersection of social, technical, and economic systems, altogether with their adaptive and sustainable integration to natural and built environments. To meet the economic and environmental mobility needs of today and tomorrow, mega development, improvement, restoration, and renewal of mixed modes of customer-centric transportation and transit systems have been rapidly initiated around the globe. This explosive urban growth can sometimes outpace essential systems planning and design; thus, ignoring intermodal connectivity, resources and energy consumption, wastes, emissions, and other environmental impacts. The interface between newly built and deteriorated assets will also require 
robust establishment of systems compatibility, safety assurance, reliability-based maintenance, uncertainty monitoring, and risk management. Accordingly, it is crucial to educate the next generation of engineers and scientists needed to meet the challenges of providing sustainable, smart, and resilient transportation and transit systems (Bringshaw, 2012).

Public and private transport modes face pressing problems of their own but simultaneously offer exciting opportunities for the research community to engage with the industry and the public. The essential modes of interdependent transport include road, rail, aviation, maritime, and pipeline. The construction, operation, and maintenance of those transport modes generate greenhouse gas emissions. Figure 1 displays the carbon footprints from transport operations (International Union of Railway, 2016; Krezo et al., 2016). Currently, advanced freight technology has led railways to be the most economically and environmentally efficient logistic system, whereas road transport emits the largest portion of carbon from transportation-related sources. Global society prioritizes social and environmental sustainability as an ambitious goal to achieve in research and development. This is evidenced by the recent Paris Agreement, a global agreement with a goal to limit global warming to $<2^{\circ} \mathrm{C}$ (United Nations Conference on Climate Change, 2015). By adopting this goal, the policy and strategy for transportation and transit systems challenge contemporary research and require new discoveries of interdisciplinary knowledge and advancement of technologies and organizational insights, which can be applied in practice.

This present article offers a summary of the key strategic areas of research and grand challenges facing researchers, engineers, scientists, and professionals with particular focuses on transportation and transit systems. This discussion is by no means comprehensive as there are so many topics that merit study, but it is impossible to fit within the context of an overview article. This paper thus serves the public and research communities in shaping and prioritizing research and development policies.

\section{TRANSLATING POLICY, STRATEGY, AND INNOVATION INTO PRACTICES AND PRODUCTS}

Transportation systems are the enabler for economic gain, social well-being, and environmental benefits to societies over

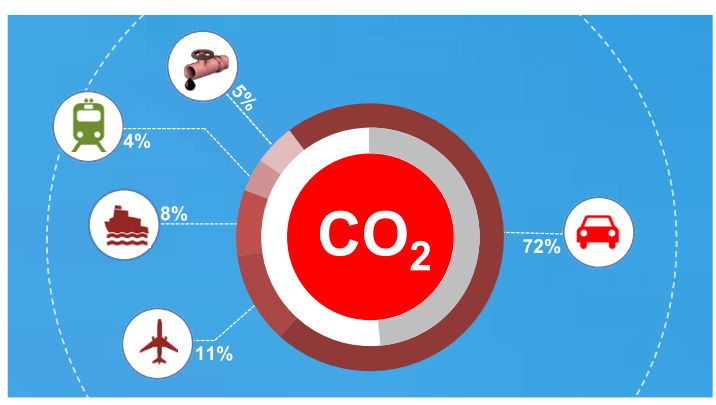

FIGURE 1 | Carbon footprints of transportation and transit systems (after International Union of Railway, 2016). their life cycle. As an emerging area of research, advancing industry practices and asset management strategies have set off opportunities ranging from developing new efficient ways for manufacture, design, construction, operation, inspection, maintenance, and renewal or disposal. More recently, the field has expanded to incorporate many inventions and applications of new sustainable materials, robotic automation, and "smarter" systems that hold great promise for the future. "A specific challenge is the linking of scales from research to practice via knowledge sharing, standardisation, and technological adoption" (Kaewunruen et al., 2015).

The need for closer collaboration in research and development between stakeholders, such as researchers, engineers, scientists, practitioners, professionals, frontline staff, organization managers, politicians, community leaders, and the public is truly vital to the success in translating policy, strategy, and innovation into practices and products. This challenge too has been observed in other major research fields, such as in advanced materials and sciences (Provis, 2015; Smith, 2015). Hayden (2014) proposed strategies to overcome such challenges through:

- Engaging scientists and researchers with engineers, practitioners, and policy makers.

- Encouraging cross-disciplinary reports of both breakthroughs and failures.

- Upscaling and retargeting fundamental methodologies and concepts to applications and practices; and potentially embracing bottom-up design and innovation.

- Promoting an open access culture of knowledge body, which benefits the public, industry, government, and academia.

- Using open and interactive peer review as a source of collaborations and equality.

\section{MONITORING UNCERTAINTIES AND MITIGATING RISKS AND THEIR INTERCONNECTEDNESS}

Emerging risks and their significant consequences with no sign of early warning can be evidenced recently by many extreme events, such as severe floods in the UK during Christmas 2015, the Nepalese Earthquakes in 2015, the 2014 Madrid train bombing, etc. Much past research in transportation and transit systems has emphasized the applications of technology in solving frontline problems in the transport industry. Although practical knowledge has been developed along with corporate knowledge, its science and technology are still insufficient to innovate, revolutionize, or transform the industry in order to cope with risks and uncertainties from the fundamental principle viewpoint. Many fundamental issues, such as choice of materials, durability, capacity, engineering properties, supporting technological systems, functionality requirements, and design concepts, remain unchanged. Together with high turnover rate of technical staff within transport industries worldwide, many incidents have repeated themselves, causing high maintenance costs, service cancelations and delays, and even loss of human life due to catastrophic incidents. Inevitably, these risk events are interconnected 
and, without appropriate monitoring and management, they introduce new risks and potentially yield wide-ranging societal consequences.

Environment-friendly, resilient, and smart transport infrastructures will enhance future capacity and adaptability to climate change and extreme events due to either natural or human-made hazards. The research challenge is how researchers, engineers, practitioners, and policy makers can share lessons learnt in the transport industry as well as implement original and unified solutions to practical problems associated with infrastructure resilience. The insights from advanced robust sensors that can be used in challenging environments and after failure will not only offer the best practice for restoring and improving transport infrastructure systems and engineering but also help to quantify systematic uncertainties and display biomimetic attributes, such as self learning, damage detection, automatic adaptation, and damage tolerance. In addition, the novel work on climate change adaptation in railway and transport infrastructure using the "systems thinking approach" will improve strategic planning, design, and maintenance of transportation and transit systems; this can lead to more adaptive and resilient transportation systems. It will establish appropriate preventative and recovery strategies for climate change, natural and unnatural hazards on transportation infrastructures, and surrounding built environments.

\section{RESTORING AND IMPROVING URBAN INFRASTRUCTURES AND THEIR CONNECTIVITY}

"It is no secret that America's infrastructure, along with those of many other countries, is aging and failing, and that funding has been insufficient to repair and replace it. Engineers of the 21st century face the formidable challenge of modernizing the fundamental structures that support civilization. The problem is particularly acute in urban areas, where growing populations stress society's support systems, and natural disasters, accidents, and terrorist attacks threaten infrastructure safety and security" (National Academy of Engineering, 2015). In addition, it cannot be stressed enough that aging and failing transportation infrastructures cannot be restored individually. This is because effective and efficient logistics of goods and services require optimal connectivity and shares of inter- and cross-modal transportation and transit systems. Accordingly, it is essential that transport modes have the ability, capability, and flexibility to connect to each other. Special challenges will be associated with those megacities with populations over 10 million where basic demands for transportation infrastructures are still problematic. Engineers and scientists will be challenged to economically provide such services more broadly and policy makers will be challenged to implement transport strategies that are more financially and environmentally sustainable for a longer term. Special attention should be given to the consumptions of resources, water, energy, environments, and the quality of life.

It is likely that climate change and air pollution will become the major criteria in decision-making for infrastructure improvements in the next few decades (McKinnon, 2010). Good design, advanced materials, better predictive technology using pertinent "Big Data," and advanced condition monitoring can improve transportation systems and also create low-carbon urban environments. These also respond to the need for routine maintenance and renewal of aging components within the transportation infrastructures, which are often required in order to assure safety and reliability of the systems (Remennikov and Kaewunruen, 2008). A challenge faced by practitioners is to achieve public support by generating social and environmental benefits (combining reduced carbon emission, reduced congestion, reduced traffic mortality, improved urbanization and land uses, increased choices of lifestyle and job, new business capabilities, avenues, etc.), which are significant positive outcomes from transportation and transit systems and their surrounding built environments (Glaeser, 2009).

Infrastructure renewal, construction, and maintenance activities are likely responsible for over $20 \%$ of carbon dioxide $\left(\mathrm{CO}_{2}\right)$ emissions (Hill et al., 2011). In recent years, this result has prompted industry to systemically estimate and manage greenhouse gas emissions from construction and maintenance activities over system life cycle. For example, a strategic framework for enabling carbon-efficient railway construction and maintenance is recommended for execution by engineers and practitioners (Kaewunruen et al., 2015). Interestingly, there has been very little work in the area of the demolition, dismantlement, repair, and recycling of materials and wastes from those deteriorated infrastructures. This topic also includes the development of lowcost, low-carbon modular design that accelerates the reduction of infrastructure backlog.

\section{ENABLING IOT FOR SAFE, SMART, RELIABLE, AND AUTOMATED SYSTEMS AND THEIR CRITICAL COMPONENTS}

Internet of Things (IoT) presents enormous opportunities for both the greatest and the worst of the intelligent transportation and transit systems. At present, aging infrastructure systems possess additional emerging risks by their inability to provide early warnings to maintainers, so that critical components can be prioritized and managed in a timely manner. Therefore, a challenge is to simultaneously enhance asset condition monitoring (bottom-up) and response prediction (top-down) of systems management, maintenance, and operation in order to provide safe and seamless transportation. Through the bottom-up approach, "Big Data," populated from asset inspection data, detection systems, and on vehicle monitoring, will need to marry with the strategic prioritization and risk management frameworks derived from the top-down approach. Appropriately managing the "Big Data" for dependable and trustworthy decision making process, which will sustainably enable top-down policy execution, is a challenge in itself. Novel smart sensors, smart materials (e.g., self-healing, self-sensing, self-cleaning, biodegradable, etc.), wireless technologies, and on-board monitoring technology such as infrastructure-toinfrastructure, infrastructure-to-vehicle, and intermodal interactive communications will be a grand challenge in order 
to modernize transportation and transit systems. Integration of sensors in cross-modal transport information model will revolutionize real time asset maintenance, monitoring, and prioritization policy. Global collaborative research focusing on health and condition monitoring will assure public safety and reliability. It will provide the pathway for full automation in the transportation and transit systems.

Internet of things also provides intelligence and interaction for borderless transport modes, especially in urban built environments. Additional to the information interface with customers, the innovation of IoT can integrate transports with human responses, travel behaviors, interjurisdictional interoperability, environmental changes, city and building ambiances, sound and noise, natural characteristics, and so on. However, issues in cyber security, artificial intelligence, and humanized robotic programing (e.g., for self-driving cars, etc.) will be constant threats to system failure. For instance, autonomous vehicles are "programed to kill" (MIT, 2015). This ethical dilemma of algorithmic morality is a grand challenge for engineers, scientists, and policy makers to solve altogether in the near future.

\section{EDUCATING THE NEXT GENERATION OF ENGINEERS, SCIENTISTS, AND PROFESSIONALS}

Social and economic growth, security, and sustainability are at risk of being compromised due to the recognized skill shortage in transportation engineering, especially for the rail transit systems. The grand challenge is not only to attract the next generation of talented people but also, more importantly, to retain them in the industry. It is essential to train and improve research skills and capability for engineers and professionals. The next generation of engineers and scientists is needed to meet the challenge of providing sustainable, smart, and resilient transportation infrastructure systems critical for maintaining regional competitiveness. Educating people to understand and manage risks associated with climate change, extreme events from natural and human-made hazards, and future operational demands will be compulsory. Capability for pre- and post-disaster management will be demanded highly in the modern but conflicted world.

\section{REFERENCES}

Bringshaw, D. (2012). Urgent need to broaden our knowledge base. Int. Railway J. Available at: http://www.railjournal.com/index.php/blogs/david-briginshaw/ urgent-need-to-broaden-our-knowledge-base.html

Glaeser, E. (2009). How Big Are the Environmental Benefits of High-Speed Rail? New York City: The New York Times. Available at: http://www.hks. harvard.edu/centers/rappaport/events-and-news/op-eds/how-big-are-theenvironmental-benefits-of-high-speed-rail

Hayden, O. (2014). Grand challenges for translational materials science. Front. Mater. 1:5. doi:10.3389/fmats.2014.00005

Hill, N., Brannigan, C., Wynn, D., Milnes, R., van Essen, H., den Boer, E., et al. (2011). The Role of GHGEmissionsfrom Infrastructure Construction, Vehicle Manufacturing, and ELVs in Overall Transport Sector Emissions. Task 2 Paper Produced as part of
Engagement between industry and academia through joint scholarly work, case studies, guest lectures, etc., will enable the technology adoption at a greater rate. In addition, researchers and scientists will significantly benefit from understanding the practicalities and physical constrains in the real world. Lessons learnt from transport infrastructure management must be shared and utilized with opened minds to assure integrated and sustainable multimodal transport planning for future cities and communities.

\section{FINAL REMARK}

We believe that this new specialty section, "Transportation and Transit Systems," will bring great opportunities as a new active research field for researchers, scientists, engineers, professionals, and policy makers in transport industry. It is very important to note that any grand challenge prediction is usually difficult and uncertain, but we are humble and very grateful for the opportunity to write this grand challenge paper. We wish to embrace open access knowledge for all mankind and assure true transparency and equality in publication. Our final hope is to accelerate and increase both quality and quantity of constructive interaction between industry (engineers, practitioners, policy makers) and academia (researchers, scientists, strategists) through the ultimate goal of free open access publications.

\section{AUTHOR CONTRIBUTIONS}

SK, JMS, and AM wrote and contributed their thoughts and experience to the grand challenge paper.

\section{ACKNOWLEDGMENTS}

The editorial input from Prof. Cholachat Rujikiatkamjorn, Drs Gearóid Ó. Faoleán, Sanjay Nimbalkar, and David Jaroszweski is gratefully acknowledged. The authors are sincerely grateful to European Commission for the financial sponsorship of the H2020-RISE Project No. 691135 "RISEN: Rail Infrastructure Systems Engineering Network," which enables a global research network that tackles the grand challenge in railway infrastructure resilience and advanced sensing.

a contract between European Commission Directorate-General Climate Action and AEA Technology plc. Available at: www.eutransportghg2050.eu

International Union of Railway (2016). Video: Train to Paris 2015. Available at: http://www.uic.org/

Kaewunruen, S., Sussman, J. M., and Einstein, H. H. (2015). Strategic framework to achieve carbon-efficient construction and maintenance of railway infrastructure systems. Front. Environ. Sci. 3:6. doi:10.3389/fenvs.2015.00006

Krezo, S., Mirza, O., He, Y., Makim, P., and Kaewunruen, S. (2016). Field investigation and parametric study of greenhouse gas emissions from railway plain-line renewals. Transp. Res. D Transp. Environ. 42, 77-90. doi:10.1016/j.trd.2015.10.021 McKinnon, A. (2010). Green logistics: the carbon agenda. LogForum 6, 1-9.

MIT. (2015). Why Self-Driving Cars Must Be Programmed to Kill. Boston. Available at: http://www.technologyreview.com/view/542626/why-self-driving-cars-mustbe-programmed-to-kill/ 
National Academy of Engineering. (2015). NAE Grand Challenges for Engineering. Available at: http://www.engineeringchallenges.org

Provis, J. L. (2015). Grand challenges in structural materials. Front. Mater. 2:31. doi:10.3389/fmats.2015.00031

Remennikov, A. M., and Kaewunruen, S. (2008). A review of loading conditions for railway track structures due to train and track vertical interaction. Struct. Contr. Health Monit. 15, 207-234. doi:10.1002/stc.227

Smith, I. F. C. (2015). Grand challenges of structural sensing. Front. Built Environ. 1:19. doi:10.3389/fbuil.2015.00019

United Nations Conference on Climate Change. (2015). Paris Agreement 2015. Available at: http://www.cop21.gouv.fr/en/
Conflict of Interest Statement: The authors declare that the research was conducted in the absence of any commercial or financial relationships that could be construed as a potential conflict of interest.

Copyright (c) 2016 Kaewunruen, Sussman and Matsumoto. This is an open-access article distributed under the terms of the Creative Commons Attribution License (CC BY). The use, distribution or reproduction in other forums is permitted, provided the original author(s) or licensor are credited and that the original publication in this journal is cited, in accordance with accepted academic practice. No use, distribution or reproduction is permitted which does not comply with these terms. 